\title{
Partial Evidence: An Enquiry Concerning a Possible Affinity Between Literary Moral Cognitivism and Moral Pluralism
}

\author{
PETER SHUM
}

\begin{abstract}
This paper begins by affirming the view that if there is a debate to be had over whether literature can convey moral knowledge, then efforts by proponents to substantiate this claim will already be necessarily conditioned by an understanding of what morality consists in, independently of literature. This observation brings to light a certain danger for the debate, namely that if participants fail to explicitly specify the ethical theory that they rely on, then the debate can seem nebulous. This raises a new question: is there an account of morality, independent of literature, which is most conducive to literary moral cognitivism, that is, which optimises literary moral cognitivism's chances of succeeding philosophically? This paper both formulates and investigates this hypothesis with reference to moral pluralism, the view that there is an irreducible plurality of foundational moral principles. It concludes that such an affinity exists, but with an important caveat: the affinity is stronger at the level of moral suggestion than the level of moral justification. This has implications for the strength of the version of literary moral cognitivism that it is ultimately plausible to endorse from a moral pluralist point of view.
\end{abstract}

KEYWORDS: literary moral cognitivism, moral pluralism, Berys Gaut, moral justification

INTERDISCIPLINARY LITERARY STUdies, Vol. 19, No. 3, 2017

Copyright @ 2017 The Pennsylvania State University, University Park, PA 


\section{INTRODUCTION}

The epistemic component of literary moral cognitivism claims that some literary works are capable of conveying moral knowledge. ${ }^{1}$ One version of this position claims that literature has a special capacity for moral suggestion, and that the moral suggestions that a work of literature can make may correspond not only to beliefs either that the reader already holds, or at least whose content the reader is already familiar with, but, importantly, to views and insights that the reader simply would not have come across were it not for reading the literary work. A stronger version of the cognitivist position claims that literature can be a source of moral justification for the very suggestions it seems to be making, which is to say that there may be occasions on which the reader does not need to turn to activities extrinsic to the encounter with a literary work in order to rationally decide that what the work is suggesting is in fact morally justified. A standard challenge to the plausibility of this stronger claim is that the advancement of a truth needs to be accompanied by the usual intellectual supporting apparatus comprising such activities as the diligent marshalling of evidence and rational argumentation. ${ }^{2}$ According to this objection, since such supporting apparatus is almost always extrinsic to the purview of literary works, and certainly extrinsic to the works that literary moral cognitivists are inclined to cite in support of their position, the stronger version of literary moral cognitivism is undermined.

It may not be assumed that this objection is premised on an equivalence between knowledge and justified true belief. The traditional tripartite account of knowledge remains a matter of epistemological dispute, most notably in the wake of Gettier-style counter-examples purporting to show that occasions can arise in which true justified beliefs do not reasonably count as knowledge. ${ }^{3}$ For the purposes of this article, it is sufficient for us merely to endorse the view that even if the traditional tripartite account of knowledge should turn out to require some kind of enhancement, any such enhancement would not have to involve a cancellation of the justification condition. Indeed, one of the main ways of responding to Gettierstyle counter-examples (by those who take Gettier's position to be sound) is to argue that the tripartite account needs to be supplemented with a fourth condition, not that the justification condition needs to be replaced. Without committing ourselves either way with respect to the traditional tripartite account, we can, I would suggest, engage substantively with what is 
epistemically at stake in literary moral cognitivism by restricting the scope of our investigations to the related questions of moral suggestion and moral justification.

Perhaps, then, the form of a convincing answer to the objection that I mentioned to literary moral cognitivism lies not in trying to equivocate over the place of justification in an account of knowledge, but in arguing that literature turns out to be capable of supporting certain modalities of moral justification. This raises a new problem. Literature may be more adept at providing justification for beliefs about moral consequences than moral duties (or vice-versa); more adept at providing justification for beliefs about moral contracts than moral virtues (or vice-versa). The philosophical success of literary moral cognitivism, then, may well depend on the account of morality that one happens to have adopted.

My working hypothesis in this article is that the debate surrounding literary moral cognitivism stands to benefit from a discursive requirement that talk of "morality" should always be tied to a particular school of moral theory. I don't deny that this approach may have its disadvantages. For one thing, thinking at the level of a particular moral theory would seem to necessarily defer final adjudication on literary moral cognitivism per se. On the other hand, failing to specify the particular moral theory that one has in mind can lend what one says a sanctimonious ring, and has a tendency to make the debate about literature and morality somewhat nebulous: it increases the risk of goal-post shifting, be it deliberate or inadvertent. ${ }^{4}$ The intended advantage, therefore, of my imposing this requirement is that it should give us a firmer grip on just what literature's potential contributions to the processes of moral justification might consist in.

Is literature qua literature neutral with respect to the moral theories it is suited to supporting, or does it have an affinity for certain moral schools? There can be no short-cuts to answering this question. The labor of addressing it will consist in selecting different moral theories in turn, and searching for reasons why such an affinity might exist in each case. I have already alluded in passing to consequentialism, deontology, contractualism, and virtue ethics. It is worth appending to this list moral pluralism, the view that there is an irreducible plurality of foundational moral principles. Are there reasons for positing an epistemologically significant compatibility between literature and the modalities of moral justification most pertinent to moral pluralism? The purpose of this article is to investigate whether such an affinity might exist. 


\section{PRIMA FACIE GROUNDS FOR HYPOTHESISING AN AFFINITY}

Moral pluralists are particularists to the extent that they maintain that what a moral agent ought to do in a given situation depends on the intricacies of the particular case. ${ }^{5}$ But this doesn't explain why moral pluralism qualifies as a moral theory in its own right. The reply which I take to be implicit in the moral theory of W. D. Ross captures much of what is attractive about the moral pluralist position, namely that particular situations have a Janus-like quality, in the sense that they are capable not only of showing what action is called for but of revealing and clarifying what one's fundamental trans-situational moral duties really are. ${ }^{6}$ This raises the possibility that a suitably devised thought-experiment could illuminate fundamental trans-situational moral duties, which explains in turn why moral pluralists might well have a moral philosophical interest in literature: literature is very often preoccupied with the detailed particularities of situations, indeed with what makes them singular, unique, and unrepeatable.

Let me elaborate on this. For the moral pluralist, moral dilemmas carry epistemological significance: they not only indicate that the agent in question has moral deliberative work to do, but are held to be potentially revelatory of what our fundamental and often competing moral duties really are. They are, in this sense, not regarded as an inconvenient symptom of moral cognitive frailty, but instead as an essential and substantive part of moral life. This provides us with the beginnings of an explanation as to why moral pluralists might be drawn to literature as a possible source of moral insight. Literary works thrive on conflict in its broadest sense, the tension which imbues the work with its movement and life. What better (what more important) conflict could there be than a moral dilemma? Moral pluralists, I would suggest, are liable to acquire an affinity for literature, in the hope of gaining insight not only into the processes of moral deliberation, but into what it is to be in a moral dilemma, into what moral dilemmas really are, and into what the underivative moral duties that are presumed to ground a given moral dilemma might actually be.

When I speak of the particularity of situations in a work of literature, I refer not only to plot but to character. As far as character is concerned, one may encounter not only those of the people depicted, but the uniqueness of an implied author who is implicitly shaping and constructing the way in which events and people are presented. I want to suggest that the way in which the reader is shown different states of mind will typically take place 
within the context of acts of imagined empathy. One must empathize with the implied author in order to understand, in all of its phenomenal richness, what it is that they are trying to convey. This is of interest to moral pluralists because, on the Rossian view at least, many of our moral duties are intrinsically social, for example, the duties of fidelity and gratitude. Such duties derive from the complex network of social relations in which human moral life takes place. Moral pluralists may therefore be drawn to literature on the grounds that the modalities of disclosure characteristic of literary experience are conducive to revelations about the essentially social nature of many of our moral duties.

My remarks so far are preliminary and somewhat speculative. But they do show that moral pluralists have grounds to be attracted to the idea that the philosophical study of literature holds a certain promise for their field. If some of the hypotheses that I have just outlined should turn out to be true, it may be found that there exist, or merely that there could exist, literary works harbouring the basis for valuable new moral philosophical insights, and this in itself is epistemologically rather interesting. Certain possibilities are surely worth exploring: that the embeddedness of sociality within a reader's literary experience could be conducive to revelations about the nature of our social duties; that a literary work's treatment of a dilemma could illuminate the phenomenology of tractive and gainful moral deliberation; that a fictional account of a particular situation in all of its uniqueness and specificity could refine our understanding of fundamental moral duties which have universal application. ${ }^{7}$ Such possibilities have an immediate bearing on our understanding of the scope of the field of moral epistemology. They are pertinent to ethical issues of the highest order and could advance the field of moral pluralism.

\section{TESTIMONY VERSUS PRACTICAL EXPERIENCE}

Two separate axiological points are worth bearing in mind here, and will inform much of this article's discussion. Firstly, moral values do not change from one situation to another, and are potentially applicable not only in all actual situations, but in all possible situations. Indeed, a large part of their moral epistemological significance lies in their constancy, for they are not governed by contingency or expediency, but themselves govern what is right, what is good, what is virtuous, and so on-in morally serious literature as much, I would suggest, as in real life. Secondly, values are not experienced 
in the abstract, but precisely in our experience of the particularity of the world. We experience values in the first instance as value-properties of other entities, for example, the courage of a (particular) soldier, the beauty of a (particular) painting, the value of a (particular) beggar's freedom. For these reasons, to the extent that literary works demonstrate a marked tendency to deal in the particularity of concrete events and situations, and (through the use of rhetoric) to implicitly evaluate objects of experience often in the very process of purporting merely to describe them, the domain of literature itself seems to be pointing outside of itself to an essentially nonliterary context for the justification of its evaluative (and hence moral) suggestions: the domain of practical experience. The domain of practical experience is, indeed, from a moral epistemological standpoint, an extremely important justificatory context, for ideas about value which bore initially the character of mere suggestion, or even plausible suggestion, can come to be internalised and embraced as one's own through the observation of, and the conscious volitional intervention in, the affairs of the world around us.

An important line of response to what I have said about the justificatory importance of practical experience centres on the observation that there are many possible experiences, for example, experiencing the trauma and aftermath of a terrorist attack, or losing a parent to Alzheimer's disease, which may be highly relevant to moral enquiry, but for which the arrangement of practical experience by the enquiring moral philosopher is not a feasible or desirable option. Moral philosophical enquiry with an interest (and, in particular, a phenomenological interest) in such scenarios will be obliged to pursue alternative modes of epistemological justification. Such modes, for example, testimony (broadly construed), imaginative introspection, and the method of reflective equilibrium (I want to argue that literature can be involved in all of these), to the extent that they are employable where practical experience is not, might be said in this respect to hold a certain epistemic advantage over practical experience.

Yet it is important that any explication of this epistemic advantage should not confuse the notion of justificatory availability with that of justificatory authority, and nor should it confuse partial justification with adequate justification. These important distinctions are illustrated in the following example. Suppose I am in a busy shopping street and I break my glasses (which have a correct prescription of, say, -5 dioptres) in an accident. Suppose further that in my bag I have an old pair of glasses made to an out-of-date prescription of, say, -2 dioptres. Then, provided the old pair helps me to see more clearly, even to some small extent, the best option 
would seem to be to put it on. But just because wearing the old pair is the best available option, it does not follow that it acquires an elevated level of justificatory authority in relation to what I believe I am seeing, beyond what is merited by a -2 dioptre pair of glasses being worn by someone whose correct prescription is -5 dioptres. The epistemological distinctions which emerge from this example (between justificatory availability and justificatory authority, and between partial justification and adequate justification) will turn out to be fundamental to my overall account of the relation between literature and moral knowledge. Both distinctions will be worth bearing in mind as we proceed through this discussion and consider different modalities of moral justification from the standpoint of moral pluralism.

For reasons which rest upon the notion (which I shall shortly discuss) of personal credibility, an individual's moral testimony could be regarded as a potential source of (at least partial) moral justification, and given our present concerns, this observation seems to invite us to consider whether there might be circumstances in which moral suggestions found in a literary work could themselves be regarded as "testimony" in some sense. One reason for developing a notion of a distinctively literary form of testimony is connected to the relation between literature and culture. Literature is an important repository of cultural values, and if a literary work is held to be of canonical status, then we expect it to illuminate, as well as resist and attempt to revise, the way in which the culture in which the work arose understood certain values. If a literary work manages on certain occasions to somehow reproduce cultural values, or represent aspects of the way in which values are wrestled with and forged within a given culture, then we might justifiably call this a kind of "cultural testimony." This is relevant to moral reflection because it is important for moral philosophers to be aware of implicit cultural assumptions, blind spots, and biases which might otherwise go undetected and unexamined.

We need to consider, however, whether the moral suggestions found in a literary work can on occasion be regarded as a form of testimony about moral values, as well as about cultural values. The analogy between reading a morally serious work of literature and receiving moral testimony from a real person is not entirely straightforward. One's acceptance of the testimony of a real person requires, as I said, his or her credibility as an attester in the relevant subject area. An attester can be held to be credible if they are sincere, competent (in a position to know), coherent, and have a track record of reliability. If I listen to a recording of Bertrand Russell and hear him assert, for instance, that "Love is wise, hatred foolish," then I may well 
be inclined to accord his statement a degree of authority greater than that of mere suggestion, because of what I know about the historical person Bertrand Russell. But this structure of testimonially grounded justification is not applicable to the views of an implied author, who is constituted heteronomously on the basis of the literary text. So there seems to be a structural reason for being more cautious about testimony given by an implied author, even if the implied author's imaginary credentials happen to be impeccable. However, an implied author can certainly be coherent, and could appear to develop a track record of reliability in moral questions. ${ }^{8}$ So a modified conception of "testimony" could be applicable to an essentially intersubjective approach to literary experience. Imaginative empathy could be said to become an experience of (at least partially reliable) literary testimony when one feels prepared, to some degree, to trust the implied author's value commitments and moral judgment on certain matters. Such tentative and qualified trust can only rationally arise when one realizes, on the basis of careful study and reflection upon a work, and preferably upon multiple works by the same author and ostensibly by the same implied author, that the implied author has a track record of suggesting evaluative and moral stances that have turned out, for the morally enquiring reader, to be worth taking seriously.

We need to observe that the tentative growth of such testimonial trust can be compromised if the implied author demonstrates in the course of a literary work tendencies toward moral inconsistency, contradiction, or incoherence. This remains the case even if the implied author occasionally displays moral brilliance, if the reader sometimes or even often finds him/ herself agreeing with the implied author's moral judgments, or if the reader finds nontestimonially grounded routes to justifying those judgments with which s/he agrees. Conversely, if the attentive reader attains a relatively clear and consistent overall apperception of the implied author's principles and approach to moral problems, then this could provide partial grounds, in conjunction with a track record of reliability, for a tentative testimonial trust in moral suggestions contained in the work, not least because a stable and reliable evaluative attitude is, by the standards of any mainstream theoretical school of ethical thought, an admirable and morally relevant trait in a moral agent. This is one modest way in which the moral epistemic status of a literary work (I leave aside aesthetic considerations in this article) can begin to be put to the test in the very context of literary experience.

However, I would still maintain that such tentative quasi-testimonial trust could not be regarded as justificatorily adequate on its own. Acceptance 
of moral testimony about values not only requires that the attester be credible, but also ultimately requires that the testimony itself cohere with the recipient's evolving set of personal moral values, which govern the individual's ability to identify what is morally salient about a given situation. I want to suggest that such value commitments do not, for the moral pluralist who does not happen to be an ethical intuitionist, flow spontaneously from ostensibly self-evident insights, but need instead to be arrived at through a complex and difficult process of reflective equilibrium. Let us look more closely at the ways in which literary experience can support such a method of reflective equilibrium.

\section{REFLETIVE EQUILIBRIUM}

It is often suggested that in the method of reflective equilibrium one tries to work one's way back to a personal set of moral values capable of underpinning and explaining disparate moral judgements, and that one has to work hard in order to discover the very values that one antecedently and unreflectively believes in. ${ }^{9}$ During this process, one rationally includes experiences that come from a wide variety of justificatory sources, drawing upon testimony, practical experience, the experience of art, and all of one's memories of these.

It would suit the cause of literary moral cognitivism if we could somehow argue that the encounter with a literary work can itself provide a setting in which entire contemplative processes aimed at morally reflective equilibrium can take place. But precisely the inverse of this picture seems now to be emerging: properly wide-ranging, eclectic, and open-ended moral ruminations themselves provide a context in which literary experience can certainly participate in, but never responsibly dominate, moral reflective activities. On this view, literature can properly be regarded as a moral cognitive participant but not, strictly speaking, as a teacher of moral knowledge. A central aspect of literature's relation to ethical thought lies in the idea that there is something special about literature's capacity for moral suggestion. I am inclined to explicate this capacity in terms of an essentially rhetorical ability to deftly deliver and implant complex evaluative perspectives into the reader's experience, a seductive ability that very often produces its effects in a manner which is phenomenologically prior to the reader's conscious grasp of how the text itself is operating. Unreasoned and lacking in explicit justification in their literary context as they may be, such 
suggestions are not ultimately justificatorily insignificant in a reader's moral life, provided that the reader feels (and I do mean feels) that a substantive or even original evaluative point has been well made, and that what is being suggested comes from an implied author whose implied moral judgment the reader has come to respect, and coheres with moral testimony that the reader has received from real individuals whom s/he thinks trustworthy, and coheres too with the reader's own practical life experiences and with beliefs the reader already holds. So justified moral understanding does seem to be capable of developing in certain ways precisely in the accumulation of disparate suggestions, suggestions which themselves are not explicitly justified in their own narrow contexts, but which often seem to be capable of corroborating, as well as conflicting with, one another, in the ongoing and in principle interminable morally reflective processes of sifting, comparing, and revisiting one's own life experiences, including one's experiences of art and of literature.

According to the model of ethical reflection that I wish to advance, then, the way we feel about individual scenarios, and the judgements we are inclined to form when considering them in isolation, have a contributory role to play but do not in the first instance govern what counts as morally right or valuable, because they need to be weighed and balanced against a multiplicity of other experiences and sources of moral suggestion before something approaching a responsibly considered moral judgement can be formed. In other words, I want to suggest that the moral intuitions that we form noninferentially and nonreflectively about particular situations should carry deliberative weight but not decisive normative authority. Yet, as McMahan indicates, there are good reasons for enquiring whether noninferential and nonreflective moral intuitions should be taken into account at all. ${ }^{10}$ We know from the social sciences that moral intuitions can originate in prejudices inculcated during one's upbringing, in religious indoctrination or in unconscious self-interest. This kind of psychological observation has led some philosophers, for example, Peter Singer, to argue that moral intuitions should be excluded from ethical deliberation. According to Singer, moral enquiry is primarily theoretical and is not validated through the consonance of its implications with our intuitions.

One way of problematizing the exclusively theoretical approach to moral philosophy is to consider the way counterexamples often function in the very context of moral theory. If a moral theoretical proposition $\mathrm{P}$ is being considered, then a counterexample will claim that there is a situation $\mathrm{S}$ in which we would not be inclined to accept that $\mathrm{P}$ is the 
case. So counterexamples cited in this way themselves appeal to our moral intuitions. While counterintuitive scientific theories such as relativity theory are capable of effectively combating our intuitions about what is really the case through their explanatory and predictive power, moral theories do not have a similar capacity to make us give up our moral intuitions, because they do not explain or predict empirical facts in this kind of way. Now it is certainly true that our moral intuitions about situations can be modified as a result of moral reflection (and very often they need to be), and that moral theoretical thought is an important part of such reflection. But as long as a moral theory produces practical conclusions that conflict with our intuitions, we do not feel philosophically comfortable about accepting the theory, even if we are unable to articulate why we feel the theory is mistaken. A good explanation for this, and one which is prominent in early twentieth-century continental philosophy, is that feelings are precisely the context in which value perceptions take place. ${ }^{11}$ The fact that moral intuitions can often be nonveridical is a reason not for discarding them from ethical deliberation, but for recognizing the importance of modifying them in the process of reflective equilibrium that I have described.

\section{INTROSPECTION}

Implicit in much that I have said is that this entire reflective process is pervaded by acts of introspection as one attempts to reach the "equilibrium" of a mature set of values. Indeed, the conscious activity of introspection seems to offer us a potentially promising line of enquiry into the processes of moral justification in a literary context. Introspection is a fairly common component of moral justificatory and confirmatory efforts. And it now seems plausible to suggest that introspection on the part of the reader is not out of place in the context of a contemplative reading experience. For one thing, the empathic understanding of a foreign personality is conducive to comparing one's own value commitments with those of the Other. In this context, the empathizer sees where value commitments are shared, and where one holds a value commitment which the Other has not acquired, or vice-versa. Similarly, it is natural during the reading process to compare one's own evaluative attitudes, moral character, and approaches to moral problems with those of the implied author. ${ }^{12}$ Literary moral cognitivists ought to be encouraged by the apparent moral relevance of introspection to literary experience, because it opens the door to the possibility that there 
may be occasions on which a reader could rationally decide that what a literary work is suggesting is in fact morally justified, without turning to cognitive activities extrinsic to the encounter with the literary work. To begin to investigate this hypothesis, I want to think about the justificatory significance of introspection within moral pluralist thought, and to consider in tandem with this the scope for such introspective justificatory activities to take place during literary experience.

There are several ways in which introspection occupies a special place within moral enquiry over against other epistemic fields. The underlying reason for this can be formulated in terms of the clarification and unfolding of one's own personal hierarchy of value commitments. One naturally seeks to acquire evidence to either corroborate or challenge suggestions of the form "A is of greater value than B" through an introspective attending to the respective depths of one's feelings for A and for B. Some acts of valuing, for example, those found in the bonds between parents and their offspring, seem to be so profound that they do not appear to be compatible with any kind of ethical deliberation. For example, a mother may introspect and find that her love for her child is absolute and unconditional. Such values, which we might call absolute values, seem to be self-verifying in the context of introspection. Yet complex and controversial moral questions articulated in the form of value comparison, for example, "Is systematic state intervention in the problem of vagrancy preferable to relying on spontaneous compassion and charity within local communities?" can rarely be resolved by means of a single act of introspection. In such cases, the moral philosopher typically proceeds by drawing on activities such as reason, debate, testimony, memory, practical experience, and perhaps even the experience of art. But during such processes, one will inevitably return again and again to introspective acts of value comparison. In the accumulation of such temporally disparate and intermittent introspection, one hopes not to oscillate endlessly between contradictory commitments, but ultimately to converge upon a settled clarification of where one genuinely stands. Moreover, the realization that one's mind is settled with respect to a particular matter is itself acquired in an act of introspection.

Questions of refining, unfolding, or converging upon a settled evaluative attitude which is congruent to one's personality and moral tenor bring us now to an important reason why literary experience can provide an important context for moral introspection. Great artworks collectively provide a variety of morally complex situations, vividly portrayed, far in excess of the range of experiences that any given person could possibly have 
in the course of a lifetime spent without art. In the case of literature, this very variety affords readers opportunities they would not otherwise have had to examine their own affective response to situations, to explore the personal value commitments that seem to motivate such responses, and to allow values that would not otherwise have to been felt to begin to unfold within their personality. It affords readers, furthermore, opportunities to reflect upon their own general moral evaluative attitude and to consider how flexible it is in assessing different situations; to reflect, also, upon how confidently one is able to pick out aspects of situations that seem to be morally salient. For any morally serious reader, such careful and attentive introspection can often turn out to be a less than comfortable experience. Indeed, part of the moral epistemological significance of literature lies in the way it can often disrupt our prejudices and leave us feeling uncertain on important moral issues.

\section{IMAGINATIVE INTROSPECTION}

In one sense, then, literary introspection can take place in moments of contemplation during the process of reading and criticism, when one introspects upon certain characteristics (e.g., stability, confidence, or their opposites) of one's own evaluative attitude toward what one has read. Yet there is a different sense in which introspection, albeit in a modified form, can be said to take place during literary experience, and which is also relevant to moral justification. This relates to imagining oneself in a counterfactual situation depicted in the work (e.g., imagining for a time not being the narrator but actually meeting for oneself the beggar described in The Old Cumberland Beggar), and attempting to explore what one's own value commitments might then be. In short, one is performing an act of introspection within an act of the imagination. Let us call this imaginative introspection.

I am making a clear distinction, then, between the conscious activities during literary experience of imaginative introspection and imaginative empathy. In Art, Emotion, and Ethics, ${ }^{13}$ Berys Gaut places great emphasis upon the moral confirmatory significance of imaginative involvement in literature, and it is clear in this context (I have in mind here in particular his book's seventh chapter, entitled “The Cognitive Argument: The Epistemic Claim”) that sometimes he is referring to imaginative introspection, and on other occasions to imaginative empathy. I mentioned earlier the relevance 
of imaginative empathy to an expanded conception of "testimony" in a literary context. For our present purposes, it is important that we now consider more closely the notion of imaginative introspection. Gaut's account of the epistemic significance of imaginative involvement in a literary work can help us to do this. ${ }^{14}$

I am in agreement with Gaut on certain general epistemological points that he makes that support the view that imaginative introspection can under certain circumstances be epistemically worthwhile and justificatorily contributive. Perhaps most fundamentally (and this point is relevant to imaginative empathy too), moral values applicable in a counterfactual situation should rationally be applicable in actuality, and vice-versa: moral values range across the set of actual and possible counterfactual situations. This means that value commitments that come to light during imaginative introspection can be regarded, if not as discoveries then at least as partially justified hypotheses, about one's own present and actual value commitments. In addition, the principle of the universalizability of moral judgments requires that moral judgements be applicable to anybody meeting the criteria proper to the judgment. Since "anybody" includes the person making the moral judgment, imaginative introspection can be an important tool in confirming or disproving such universalizability.

Gaut makes further valid points which are pertinent to imaginative introspection when he observes that some epistemic advantage is held by the imagination over direct experience in virtue of the facts that (1) two mutually exclusive future possibilities can both be imagined and compared, but not both directly experienced, and (2) that some experiences are so unlikely or undesirable that one is rationally obliged to resort to the imagination in order to find out more about how one would respond to them. ${ }^{15}$ I do not disagree with these last two claims in themselves (in fact, I think they are important observations) but I am concerned that the manner in which Gaut deploys them seems designed to make them serve as a consolation for his reluctant admission that the imagination has "lesser epistemic authority"16 than practical experience. Granted, Gaut is careful never to explicitly claim that justificatory availability can compensate for a shortfall in justificatory authority. But he also manages to avoid drawing much attention to the important conceptual distinction between justificatory availability and justificatory authority, and this omission risks making his position appear more convincing than it really is. I will also want to suggest in due course that there are good reasons for thinking that Gaut needs to pay more attention to the distinction between partial justification 
and adequate justification. ${ }^{17}$ To begin to see why this might be the case, we need to look more closely at his account of the potential role for literature in imaginative introspection.

During practical moral deliberation, one is often concerned not simply with the set of all possible situations, but with situations which correspond either to the way the world is now, or to the way the world will be in the future: one is concerned, in short, not only with the possible, but with reality, and with the way reality is likely to be. One context in which realism becomes important is when we seek to seriously investigate kinds of possibilities that seem to be intricately bound up with what it is to be human. One need only turn to Shakespeare to find examples of the kind of possibilities that I have in mind here. Somebody who is both insecure and jealous may be inclined toward murder. The Machiavellian machinations of somebody gripped by political ambition may end in personal disaster. ${ }^{18}$ These are not laws of human behavior, but there is truth to them to the extent that they delineate patterns that have recurred throughout human history, and to the extent that they can indicate on certain occasions what is likely to be the case, or how matters are likely to end. If, as part of a serious moral enquiry, one is to try to imagine such a situation, or even to imagine being caught up in one, then one's imaginings would need to be informed and constrained by justified psychological beliefs concerning the way the people involved would be likely to behave, and what their motivations would be likely to be. Psychological realism is therefore particularly important to the exercise of the imagination in the context of moral enquiry.

But there can also be occasions on which one's understanding of what is likely will also need to be informed by what is known scientifically or statistically. Consider the following example. Suppose someone (let us call him William) is inclined toward believing that there should be no systematic state intervention in the problem of vagrancy and that homeless people should have to rely upon spontaneous charity from the local community. As part of his moral deliberation, William decides to investigate the universalizability of this judgment by imagining himself being a homeless person living rough in the countryside of, say, northern England. His intention is to see if, in the imaginary situation, he still believes there should be no state intervention. However, before William even begins his imaginative introspection, he realizes that he is going to have to do some research into overnight temperature ranges for this part of England, and some statistical research into the probability of a homeless person in this part of the country receiving charitable assistance. Imaginative introspection, then, in a moral 
context, often requires background psychological knowledge and understanding of human motivations, but can also require many other kinds of knowledge, such as scientific or statistical. It is important for our present purposes to note that the acquisition of such background knowledge is not part of the imaginational activity itself, but a prerequisite for it.

Gaut makes some helpful points regarding how literary works and their careful readers can contribute to the project of attempting to imagine in a realistic manner. For one thing, many literary works are not aimed at fantasy but at realism, and such works can guide the reader into realistic imaginings. The putative realism of a work needs to be independently verified, and this is addressed by one aspect of Gaut's account of using the imagination in a disciplined way: one's imaginings must fit with the available independent evidence and cohere with things that one already knows. This is surely right, but I believe two further points of qualification, to which Gaut pays insufficient attention, need to be added. First, the source of verification involved here is not the literary work, but background knowledge (for example, psychological, scientific, statistical) which is extrinsic to the literary work. Second, it seems strange to try to wrap all of the verificatory effort into imaginational activity, since an important part of such effort (that is, gathering background knowledge) is a prerequisite for the imaginational activity. Granted, the literary work is contributing to imaginative introspection by guiding the reader into realistic imaginings, and imaginative introspection can contribute to moral justification. So at this stage we need to limit our acceptance of Gaut's position to the view that literature can contribute partially to the processes of moral justification by means of imaginative introspection.

Fidelity to reality, and more specifically to the psychological and sociological facts about human life, and to scientific facts about the empirical world, then, is a characteristic of imaginative content that can support moral enquiry. But there are at least two other characteristics worth considering: vividness and completeness of scope. Vividness in this context really refers to richness of detail, and is therefore not equivalent to fidelity: an act of the imagination may be faithful to reality but have a disappointing level of vividness, and vice-versa.

Vividness is important to imaginative introspection because the more vivid one's imaginings are, the more likely one is to become emotionally involved, and to form clear evaluations with respect to the people and situations that are being imagined. If one imagines a situation vividly, then it is as if (but only as if) one is perceiving the situation for oneself. Great 
literary works typically display an assured yet unostentatious ability on the part of the implied author to depict scenes vividly, and thereby to facilitate an absorbed imaginative involvement on the part of the reader, in which the reader's deepest moral commitments may come to light, perhaps even for the first time. ${ }^{19}$ Part of the burden also falls upon the committed reader, who with sufficient practice can develop an imaginative faculty capable of great vividness, sometimes even on the basis of relatively meagre levels of rich detail provided within the literary text.

There is, nonetheless, a tension here that we need to be wary of. Vivid imaginings, for all their importance within the processes of rational moral enquiry, may not be as straightforwardly conducive to moral clarity as one might initially think. Vivid imaginings are essentially perspectival: it is as if one were really there, perceiving events not only from a certain spatial viewpoint, but from a certain personal viewpoint. One finds that, purely due to the way a literary work has been written, certain aspects of vividly imagined situations are more salient than others. Vivid imaginings, then, do not constitute a pristine and neutral horizon for moral contemplation, but are instead already invested with and pervaded by myriad implicit value commitments which work to condition any subsequent moral deliberation. Part of the difficulty here is connected with the fact that literary works often produce their complex evaluative effects prior to the reader's grasp of how the text's rhetoric is operating. Even the most ostensibly dry and clinically detached police procedural novel can deeply implant within the unsuspecting reader, through subtle and understated turns of rhetoric, through the inclusion of certain ostensibly minor details and the exclusion of certain others, value perceptions that can skew the way situations are understood, that influence which characters one feels sympathy for, that can determine to some extent whether the reader feels suspicious, uneasy, trusting, and so on. The capacity of a literary work to seduce the reader into feeling a certain way is partly what distinguishes literature from scientific texts, for example, or from an impartial police witness statement suitable to be considered in a court of law. Paradoxically, then, while the very vividness of the imaginings that can take place during literary experience can support imaginative introspection, the perspectival character of such vivid imaginings suggests that further justificatory work will still be required. If moral justificatory progress is being made here, its justificatory character is contributive, not decisive.

The double bind that seems now to be emerging might be restated as follows. Allowing literature qua literature to contribute where it can to moral 
justificatory efforts (in particular those in which imaginational activity is pivotal) requires concessions on the part of the moral enquirer to literature's perspectivism, and to that extent a displacement in these phases of moral activity of the pretensions to discursive objectivity that are sometimes held to be of a piece with rational moral enquiry. For those of us even remotely inclined to explore the extent of the potential cognitive significance of the imagination, the answer surely cannot be that we aim for a wholesale repression of vivid imaginings from moral philosophical activity.

A better alternative might be to indulge at certain moments the biases and tendentiousness that vivid imaginings (especially those deriving in some way from literary experience) to a greater or lesser extent usually bring, and then seek in due course to draw them back into broader overarching processes of rational moral deliberation. The paradox is that while realistic vivid imaginings can support moral justification in the ways that I have discussed, their doing so involves adopting and emphasizing certain perspectives, and closing off others which could still be pertinent to the moral issue in question.

The problem we still face, in other words, could be described as one of completeness of scope, if completeness of scope in imagining a morally demanding situation requires the ability to see the situation from all morally relevant angles. This corresponds to the third characteristic of imaginative content that I mentioned earlier. It is not unheard of for a literary work to repeatedly return to the same scene, describing it each time from a different perspective, and perhaps even from the points of view of different characters. ${ }^{20}$ This is one way in which a literary work can begin to mitigate the problem of completeness of scope.

I want to suggest, however, a more general way of broadening one's perspectival scope on moral problems which can still involve imaginative introspection in the context of literary experience, and which does not rely upon a given literary work treating the same situation from multiple perspectives. This more general solution is for the reader to seek out multiple works which all engage with the same, or very similar, moral issues, and to undertake activities of imaginative introspection during the encounter with each work. This approach takes advantage of the facts not only that one's value commitments tend to come to light most saliently during the actual experience, or vividly imagined experience, of particular situations, but also that precisely these value commitments, if truly one's own, in principle span all possible situations, and are therefore certainly applicable across multiple literary works which aspire, minimally, to portraying possible situations. 
For example, having studied Wordsworth's The Old Cumberland Beggar, one might then seek out other works by Wordsworth, and then works by other authors, which undertake morally serious thematic enquiry into the nature of encounters with homeless people, or more generally, with individuals living, in some sense, on the margins of society. The exploration of a complex moral issue of this kind, I want to suggest, can always benefit from being investigated in different ways, and in particular by exploiting the moral epistemic advantages that can flow from imaginative involvement in the perspectives belonging to different personalities.

\section{CONCLUSION}

My underlying point, which is supported by the different lines of investigation pursued in this paper, is that moral philosophical enquiry, in an approach to ethics compatible with both literary moral cognitivism and moral pluralism, is best conceived in gradualist terms, and that important moral issues with which literary works very often substantively engage are rarely if ever capable of being exhaustively or even adequately "decided" on the basis of the putative insights contained within a single literary work, no matter how seemingly thorough and convincing that work's thematic elaborations might be. We have certainly found that literature can contribute substantively to the processes of moral justification, and that this contribution can gain greater justificatory authority if multiple relevant literary works are taken into account. Even so, we must accept that the nature of literature's role in moral justification ultimately remains contributive rather than decisive. Indeed, at every turn in this paper, we have found grounds for epistemological caution in relation to the question of literary moral cognitivism from a moral pluralist point of view: caution, because literary experience itself points beyond literature to practical experience as a proper domain for moral justification; caution, because literature's status as a potential source of moral testimony is partially compromised by the fact that the implied author is not ontically transcendent to the work, but instead is constituted heteronomously on the basis of what is given in the text; caution, because the complex processes of reflective equilibrium necessarily take in a variety of sources of experience and justification, of which literature is but one; caution, because part of the verificatory effort involved in ensuring imaginative realism is extrinsic to literary experience; and caution, because the perspectival character of realistic vivid imaginings 
evoked by any given literary work structurally entails a risk of excluding morally pertinent ways of viewing a depicted situation, and is liable, in virtue of the very deployment of rhetoric that renders literature precious to us, to be pervaded by implicit and even subtly tendentious evaluative suggestions.

The thesis of this article is therefore that there are important affinities between literary moral cognitivism and moral pluralism, at the levels of both moral suggestion and moral justification, but that the affinities are not sufficiently tight to support the strong version of literary moral cognitivism which I mentioned in my introduction. For the reasons identified in the course of this discussion, I recognize that literature qua literature does have an epistemologically significant capacity for moral suggestion, but that it is ultimately misleading to claim that literature teaches us about morality, or that literature can strictly speaking be regarded as a source of moral knowledge, owing to the conspicuous frangibility of literature's various contributions to the processes of moral justification. Cognitivist protestations which involve resorting to the mantra that putative knowledge need not be indefeasible begin to have the look of straw clutching when, as I have argued, it becomes in the end rather difficult to accept in good epistemic conscience that literature fully satisfies the justification condition from a moral pluralist perspective.

DR. SHUM is Associate Fellow of the Higher Education Academy in the UK, and has taught undergraduate modules in logic, philosophy of language, history of modern philosophy, and aesthetics. He has research interests in phenomenology, literary theory, aesthetics, and ethics. He is an alumnus of the University of Warwick, where he also taught in the philosophy department.

\section{NOTES}

1. This paper adopts the terminology of "moral cognitivism" developed in Gaut (2007), e.g., 136.

2. For an example of this kind of challenge, see Lamarque \& Olsen (1994), 368.

3. Let me provide some further clarification of what I mean, as far as this article is concerned, by "Gettier-style counterexamples." Sometimes a rational person may arrive, for justifiable reasons, at a belief which, though true, is in some sense fortuitously so. Consider the following example. Suppose my watch stopped yesterday at 3 p.m. without my knowledge. Today I may look 
at my watch and, seeing that it says 3 p.m., conclude that it is 3 p.m., when the time of day is indeed 3 p.m. I may have very good reasons for trusting my watch. For example, it may be a highly respected make of watch; or it may be a watch that was recommended to me by a friend who is a recognized watch expert. The point is that although I have arrived at a justified true belief, that the time is 3 p.m., outside observers of the situation may be inclined to have reservations about the claim that I have acquired knowledge that it is $3 \mathrm{p} . \mathrm{m}$. This would suggest, in turn, that there is something inadequate about the claim that knowledge is justified true belief. For further detail on Gettier's position, see Gettier (1963).

4. It might be asked if I have any particular scholars in mind when I raise the problem of nebulousness. My response is as follows. I don't think it would be fair or conducive to constructive scholarly debate to track down and cite any particular examples of nebulousness. Even if I do have one or two scholars in mind, I don't doubt that their contributions to this field far outweigh any weaknesses in their positions. My intention in highlighting the question of nebulousness at this early stage is really to register at a meta-argumentative level a theoretical risk for the debate. It is a risk which may materialize in at least two different ways. One way is for a scholar's line of thought to terminate in the bathos of ascribing to some well-known literary work the intimation of a moral platitude with which no commentators would be inclined to disagree. Another way is to be found in an unnecessary retreat into a reader-response theory of literary studies, according to which any insights to be gleaned from the work will be reader relative. I do concede that the temptation to gloss over the central philosophical debate concerning what morality consists in can be strong, as if one were somehow clearing the decks for the main task in hand, namely the question of literary moral cognitivism as such. The drawback is that the moment one abstracts too far away from what morality consists in, one begins to lose purchase on what literature can contribute to moral reflection; on the nature of the insights that literature might be able to suggest; on the modes of moral justification that literature would need to be able to support. In short, my point here is that if the moral theoretical stratum of the problem is neglected, our debate will have to rely too heavily on intuitions when assessing the validity of putative examples of moral elucidation in literature.

5. For an influential exposition of a strong version of the moral particularist position, see Dancy (1983), which begins as follows: “This paper is about the non-existence of moral principles. Its conclusion is a thorough particularism, according to which our ethical decisions are made case by case, without the comforting support or awkward demands of moral principles."

6. As Berys Gaut points out, the moral theory developed by W. D. Ross has both pluralist and intuitionist aspects, and these aspects are separable. The pluralist aspect holds that there is an irreducible plurality of foundational moral principles. The intuitionist aspect holds that if a moral philosopher reflects carefully enough, then each of the foundational moral principles turns out to be self-evident. See Gaut (2002), 137. 
7. An example of the kind of work that I have in mind here is Graham Greene's The Power and the Glory. In this novel, a persecuted priest finds that, by pursuing his vocation, he may endanger both himself and the Mexican peasants that he wishes to serve.

8. It might be asked what would constitute a good track record of reliability with respect to moral judgments. Let me break this down into two questions. Firstly, could there even be such a thing as a track record of reliability in a literary context, when the implied author is often entirely a product of someone's imagination and does not correspond to a real person who is distinct from the literary work? Secondly, even if an implied author appears to have some kind of track record, what kind of criteria would it be possible to apply when deciding if the track record is a good one? (1) The first question is tied into theoretical debates concerning what it is, fundamentally, to encounter and study a literary text. It is not my intention to try to legislate for how scholars ought to go about reading literature, but it is certainly central to many approaches, including those, for instance, found in the Geneva School, to construe the encounter with a literary work in intersubjective terms-in terms, that is, of encountering another person replete with their own mind, personality, and conscious interiority. One apperceives through a careful studying of the text the implied author's feelings and motivations, and the moral stances, attitudes, and dispositions that such feelings and motivations seem to be suggesting. In this case I would argue that it is intelligible to speak of an implied author's track record of reliability, on the grounds that the encounter with the implied author is conceived as being sufficiently similar, in substantive respects, to an encounter with another person. (2) On the second question (concerning criteria), assuming that one has adopted an approach which does construe the encounter with a literary work in the kind of intersubjective terms that I have described above, it would be appropriate to adopt criteria which take into account both the quantity and the quality of the moral suggestions that the reader has detected. Granted, readers may not always calibrate the criteria that they apply entirely prudently; but this is no different from the criteria that we might be inclined to apply when meeting real people in everyday life.

9. McMahan (2001), 105-6.

10. McMahan (2001), 94-95.

11. The thinker that I primarily have in mind here is Max Scheler. The work in which his theory of values is developed in the greatest detail is Scheler (1973). In addition, I also have in mind Edith Stein, whose work on empathy Stein (1989) is influenced by Scheler's position.

12. An example of the kind of work that I have in mind here is Women in Love by D. H. Lawrence. In this novel, Lawrence employs dialogical exchanges between various characters to explore differing views about marriage, relationships, and sexuality. For instance, as the novel draws to a close, Rupert and Ursula have a conversation in which they disagree about the similarities and differences between heterosexual and homosexual love (481). This kind of articulation by 
Lawrence of conflicting views is conducive to the reader introspectively comparing what is said with his or her own attitudes.

13. Gaut (2007).

14. The transition which now takes place toward a discussion of the role of imaginative introspection marks an intensification of this paper's scrutiny of what I take to be Berys Gaut's version of literary moral cognitivism. This should not be interpreted as a discontinuity in the nature of the discussion which is unfolding. On the contrary, the underlying agenda remains the same: to investigate the contributions that literature can make to those modes of justification which are particularly germane to moral reflection. It is an enquiry similar in approach and purpose to that which Gaut himself undertakes in Chapter 7 of Art, Emotion and Ethics (2007). Any critique of Gaut formulated in the remainder of this paper is developed not for its own sake, but purely in support of the overall purposes of this paper.

15. Gaut (2007), 156.

16. Gaut (2007), 156.

17. In many other important respects, of course, my debt to Gaut (2007) is significant.

18. The Shakespearean examples that I have in mind here are, in the case of jealousy, Othello, and, in the case of political ambition, Richard III.

19. In my opinion, John Updike is a master at vividly describing quotidian details in a memorable and arresting way. Here is an example from Rabbit Is Rich, 421: "the pink patches in his face glowed red and his lips tightened back from his teeth so you thought all the more of his skull. Dirty yellow teeth loaded with gum-line fillings, and his mustache never looked quite even, or quite clean."

20. For example, in the Julian Barnes novel Talking It Over, the three main characters, Stuart, Gillian, and Oliver, provide different accounts of the same events. The effect is a heightened sense of the subjectivity of memory.

\section{WORKS CITED}

Barnes, J. Talking It Over. London: Picador, 1992.

Dancy, J. (1983). 'Ethical Particularism and Morally Relevant Properties'. Mind 92.368 (1983): 530-47.

Gaut, B. "Justifying Moral Pluralism," in Moral Pluralism: Re-evaluations, ed.

P. Stratton-Lake. Oxford: Clarendon, 2002.

Gaut, B. Art, Emotion and Ethics. Oxford: Oxford University Press 2007.

Gettier, E. L. "Is Justified True Belief Knowledge?" Analysis 23 (1963).

Greene, G. The Power and the Glory. Harmondsworth: Penguin, 1983.

Lamarque, P., and S. H. Olsen. Truth, Fiction, and Literature: A Philosophical

Perspective. Oxford: Clarendon Press, 1994.

Lawrence, D. H. Women in Love. London: Penguin, 2000.

McMahan, J. "Moral Intuition," in The Blackwell Guide to Ethical Theory, ed. H.

Lafollette. Oxford: Blackwell, 2001. 
Scheler, M. (1973), Formalism In Ethics and Non-Formal Ethics of Values (1913-16), Trans. M. S. Frings and R. L. Funk. Evanston: Northwestern University Press, 1973.

Stein, E. On the Problem of Empathy. Trans. W. Stein. Washington D.C.: ICS Publications, 1989.

Shakespeare, W. King Richard III. Ed. A. Hammond. London: Methuen \& Co., 1981. Othello. London: Penguin, 1994.

Updike, J. A Rabbit Omnibus. London: Penguin, 1991.

Wordsworth, W. The Selected Poetry and Prose of Wordsworth. Ed. G. F. Hartman. New York: Meridian, 1980. 